siting a refinery in the Isle of Grain; of the engineering, technical, political and local environmental difficulties which had to be overcome in planning such a vast enterprise to meet, at the time, the unforeseeable demands for petroleum products years ahead. In this graphic account are linked some of the well-known personalities in the Company who were concerned with the initiation and construction of this plant, admittedly involving highly organized team-work under their direction, without which the scheme could never have met with success. It makes fascinating reading, because the human effort involved in overcoming natural difficulties of the site, weather, floods and other hazards, inevitably bound up with industrial developments in raw estuarine territory such as the Isle of Grain (common to so many of the world's major refinery locations), is so modestly described.

The third article, entitled "And Before the Ink was Dry", is a technical account of the growth of this Kent refinery; it brings the whole project up to date. "The establishment of a new 'grass-roots' refinery must be influenced by the market requirements, the technology available at the time and the forecasts of the foreseeakle future. The history of Kent Refinery is not peculiar in these respects but the seventeen years since the project was conceived and the ten years since the first oil was processed in the refinery have been years of unprecedented change in all these directions." It is recorded that the through-put in the first full year of operation was 3.4 million tons; the 1962 figure is 9.8 million tons. Before the ink is dry in drafting new specifications for extensions to the plant, operations and products-output, technical advances move apace and overtake contemporary ideas. The oil industry is one of the most flexible of all; it is the sense of urgeney and adaptability which have made it the dynamic influence it deservedly exerts in our times.

\title{
GRAVITATION IN THE U.S.S.R.
}

$\mathrm{M}$ A. GARBELL of the Garbell Research Foundation, - San Francisco, California, believes that gravitation together with its relativistic and quantum theoretical aspects constitutes the final problem of modern theoretical physics, and consequently he has taken considerable trouble to produce a detailed report of the First Soviet Gravitation Conference which was held during June 27-30, 1961, at the Sehool of Physies, Moscow State University *.

The report consists of two parts. Part 1 , composed by M. A. Garbell, contains synopses and abstracts of each of the seven subject sessions into which the conference was divided, together with analytical comments, annotations and guiding references to other pertinent papers. Part 2 consists of a full translation from the Russian of tho condensed versions of the eighty-three contributions presented to the conference and which were published by the State University in 1961. The first two sessions were devoted to the classical theory of gravitation, and the subsequent sessions to non-Riemannian generalizations of geometry, the quantum theory of gravitation and non-linear equations, experiments, cosmology and gravimetry respectively.

In his general review, M. A. Garbell comments that the conference was devoid of any momentous breakthrough, and though the assembly consisted of members of the foremost Soviet schools of thought on gravitation, relativity and quantum physics-with the conspicuous

* Garbell Research Foundation, San Francisco. Garbell Aerospace Series, No. 9: Theses of the First Soviet Gravitation Conference held in Moscono in the Summer of 1961 . By Maurice A. Garbell. Pp. 130. (San Franciseo,
California: Garbell Research Foundation, 1714 Lake Street, 1963.) 7.50 dollars. absence of V. A. Fok and representatives from European satellite countries-the gathering seemed painfully perplexed with endless questions, nearly all of which remained unanswered. In general, theoretical concepts based primarily on Einstein's theory of relativity were advanced, but there were exceptions such as Petrov's classification of Einstein spaces, Ivanenko's contributions towards a non-linear unitary field theory, the atomic and molecular clock satellite programme of the Dubna group, and Smorodinskiy's ideas on the neutrino-antineutrino world.

Academician Blokhinstev commented that any assumption that the gravitational charge of an antiparticle might be negative, or even that the gravitational charge of a photon might be zero, would constitute an insurmountable paradox. Kadyskevskiy proposed the $\beta$-decay length of weak interaction as an irreducible unit for the smallest finite spatial building block of the universe. Two proposals were made by the Joint Nuclear Research Institute (Dubna) group for gravitational experiments in the laboratory. The first was an experiment in which the emission of gravitational waves could be detected without the necessity for setting up a receiver-absorber to pick up the emitted waves, and the second a vertical beam experiment for the detection of any negative gravitational mass of the $K$-meson antiparticle by means of an interference method first described by M. Good of the University of Wisconsin.

Soviet support in cosmology is for a non-homogeneous and anisotropic universe and there were strong suggestions that the neutrino exerts a substantial effect on the determ. ination of the geometry of the universe.

S. WEINTROUB

\section{SICKLE-CELL AN/EMIA}

A $\mathrm{N}$ investigation of the clinical manifestations of sickle-cell anæmia found in the Wankie district of Southern Rhodesia, prepared by Dr. Trefor Jenkins of the University of Natal, indicates that the disease is similar in most respects to that found in the Congo Republic, and differing only slightly from that found in West and East Africa*. The more marked differences between the condition seen in Africa and the United States have been confirmed.

Although the condition is not common in Southern Rhodesia, it is felt that many cases of sickle-cell anæmia have passed unrecognized over the years because practitioners have been unaware of the African 'variety' of the

* The Central African Journal of Medicine, 9, No. 8; August, 1963. disease. Most medical text-books still describe the disease as it occurs in the American Negro, between the ages of five and ten years, when it is characterized by arthralgia. fever, anæmia, cardiomegaly, abdominal pains simulating one of a number of surgical emergencies, chronic punchedout ulcers about the ankles and a variety of neurological disturbances resulting from cerebral thromboses.

The disease as it occurs in Africa affects a much younger population, the average age at diagnosis varying from just less than four years in Nigeria to just more than one year in the Congo Republic. Hendrickse raises doubts concerning the very young age at diagnosis in the Congo series. Because the diagnosis had not been confirmed by electrophoretic examinations of the hæmoglobin, he 